\title{
Expression of selected regulatory molecules on the CD83+ monocyte-derived dendritic cells generated from patients with laryngeal cancer and their clinical significance
}

\author{
Janusz Klatka $\cdot$ Ewelina Grywalska $\cdot$ \\ Maria Klatka • Magdalena Wasiak • \\ Adrian Andrzejczak · Jacek Rolinski
}

Received: 7 December 2012/Accepted: 17 April 2013/Published online: 30 April 2013

(C) The Author(s) 2013. This article is published with open access at Springerlink.com

\begin{abstract}
B} 7 \mathrm{H} 1$ and $\mathrm{B} 7 \mathrm{H} 4$ overexpression is associated with inhibition of the immune system in many solid tumors, and altogether with CD200 molecule plays an important role in tumor invasion by promoting malignant transformation. However, there is no report about impact of these molecules on laryngeal squamous cell carcinoma. The objective of the present study was to assess by means of flow cytometry the expression of B7H1, B7H4, CD200, and CD200R on CD83+ monocyte-derived dendritic cells (Mo-DC), pulsed with autologous tumor cell lysates (aTCL) in patients who suffer from G1, G2, or G3 laryngeal carcinoma (LC, $n=60$ ) in comparison to healthy donors ( $\mathrm{HD}, n=15$ ). It has been demonstrated that median value of the percentages of $\mathrm{CD} 83+\mathrm{B} 7 \mathrm{H} 1+, \mathrm{CD} 83+$ $\mathrm{B} 7 \mathrm{H} 4+$, and $\mathrm{CD} 83+\mathrm{CD} 200+$ cells were higher in $\mathrm{LC}$ patients than $\mathrm{HD}(p=0.041, p \leq 0.0001$, and $p=0.02$, respectively). Mean fluorescence intensity (MFI) of CD200, CD200R, B7H1, and B7H4 on the Mo-DC pulsed with aTCL of the patients was also higher than on the MoDC of HD $(p \leq 0.0001, p \leq 0.0001, p=0.002$, and
\end{abstract}

\section{J. Klatka · M. Wasiak · A. Andrzejczak}

Department of Otolaryngology and Laryngeal Oncology, Medical University of Lublin, Jaczewskiego 8 Street,

20-954 Lublin, Poland

E. Grywalska $(\varangle) \cdot$ J. Rolinski

Department of Clinical Immunology and Immunotherapy, Medical University of Lublin, Chodzki 4a Street,

20-093 Lublin, Poland

e-mail: ewelina.grywalska@gmail.com

M. Klatka

Department of Pediatric Endocrinology and Diabetology,

Medical University of Lublin, Chodzki 2 Street,

20-093 Lublin, Poland $p \leq 0.0001$, respectively). The highest MFI levels of all molecules were noted in grade $3 \mathrm{LC}$. The aforementioned results prove that there is a relation between the presence of laryngeal cancer and the expression of $\mathrm{B} 7 \mathrm{H} 1, \mathrm{~B} 7 \mathrm{H} 4$, CD200, and CD200R regulatory molecules on the CD83+ Mo-DC pulsed with autologous cancer cell lysates. Strong association of LC grade and the tested antigens expression suggests a critical role for these proteins in LC biology.

Keywords B7H1 - B7H4 - CD200 - CD200R . Monocyte-derived dendritic cells · Cell lysates . Laryngeal cancer

\section{Introduction}

Laryngeal cancer is one of the most commonly occurring malicious cancers of head and neck region, with squamous cell carcinoma as the predominant histologic type [1,2]. In spite of their constant development, the classical therapeutic methods, such as surgical procedures or radiotherapy are not sufficiently effective in prolonging the survival time of cancer patients and improving the quality of their lives [3]. Therefore, the increasing morbidity and unsatisfactory effects of treatment, especially in cases of advanced laryngeal carcinoma (LC), stimulate the researchers to develop new more effective therapy schemes including immunotherapy with the use of the dendritic cells (DC) and/or monoclonal antibodies [4]. Unfortunately, an optimal method of treatment with DC has not been developed yet due to the limited knowledge of the biology of DC, the influence of cancer antigens on their functions, and the expression of co-stimulatory molecules which are extremely vital as far as the interaction of DC with other cells is concerned [5]. 
B7H1 and B7H4 molecules belong to newly discovered proteins from B7 family. B7H1 molecule demonstrates hindering properties toward the immunological response of T lymphocytes [6]. B7H4 molecule was identified in 2003 as a co-stimulatory molecule which is vital in the process of hindering the proliferation of $\mathrm{T}$ lymphocytes and blocking the production of cytokines by Th1 and Th2 subpopulations. Its high expression on the surface of cells of some cancers may lead to an assumption that it is a marker of carcinogenesis [7]. CD200 (formerly OX2) is a type 1a membrane protein with two extracellular immunoglobulin superfamily domains, a single transmembrane region, and a short cytoplasmic tail [8, 9], broadly expressed on a variety of cell types, such as some DC, thymocytes, $\mathrm{T}$ and $\mathrm{B}$ lymphocytes, neurons, kidney glomeruli, syncytiotrophoblasts, and endothelial cells [10], which delivers immunoregulatory signals through binding to receptors expressed on monocytes/myeloid cells, including monocyte-derived dendritic cells (Mo-DC), and $T$ lymphocytes. Signals delivered through the CD200:CD200R axis have been shown to play an important role in the regulation of anti-tumor immunity. Overexpression of CD200 has been reported in a number of malignancies and on cancer stem cells [11] and this molecule may play roles in local tumor invasion as well as augments the metastatic capacity of squamous cell carcinoma [12].

The main aim of the present study was to assess the expression of $\mathrm{B} 7 \mathrm{H} 1, \mathrm{~B} 7 \mathrm{H} 4, \mathrm{CD} 200$ and CD200R on CD83+ Mo-DC, pulsed with autologous tumor cell lysates (aTCL), of patients who suffer from LC in comparison to healthy donors (HD). To the best of our knowledge, the present publication is the first to describe the mentioned issue. Thus far, the expression of the aforementioned molecules has not been assessed yet on DC in patients with LC. The analysis seems to be essential for many reasonsit will allow us to determine whether it is possible to derive fully efficient DC from patients with LC, which respond to cancer antigens, and what is the influence of LC antigens on Mo-DC. We have also assessed the impact of LC in various histological grades on the expression of $\mathrm{B} 7 \mathrm{H} 1$, B7H4, CD200, and CD200R molecules.

\section{Materials and methods}

Patients and healthy controls

Sixty male patients treated surgically for primarily diagnosed squamous cell carcinoma of the larynx, without preoperative treatment, were included in the study. The diagnosis of squamous cell carcinoma of the larynx was established by histopathology of tumor samples. The mean age of patients was $64.72 \pm 9.29$ years (ranging from 45 to 79 years; median 65.8).

Peripheral blood from 15 healthy male donors, at the mean age of $57.68 \pm 11.95$ (ranging from 43 to 73 years; median 59), was used as a control. In patients and HDs, peripheral blood WBC was within the normal range between 4 and $10 \mathrm{G} / \mathrm{L}$.

None of the patients and controls had signs of infection at the time of investigation and for a month before surgery none had been taking drugs of known influence on the immune system. None of the patients or HDs had undergone blood transfusion. Persons with allergic diseases in anamnesis were excluded from the study. The research protocol was approved by the local Ethics Committee and all patients gave written informed consent.

\section{Isolation of the peripheral blood mononuclear cells}

Peripheral blood mononuclear cells (PBMCs) were separated from heparinized venous blood of the patients and the HDs by density gradient centrifugation using Gradisol-L (Aqua Medica, Poland) and centrifuged for $20 \mathrm{~min}$ at $700 \mathrm{G}$. PBMCs were collected and washed twice in phosphate-buffered saline (PBS) without $\mathrm{Ca} 2+$ or $\mathrm{Mg} 2+$ (Biochrom AG, Germany). Interphase cells were washed twice in $\mathrm{PBS}$ without $\mathrm{Ca} 2+$ or $\mathrm{Mg} 2+$ (Biochrom $\mathrm{AG}$, Germany) and then resuspended at $0.5-1 \times 10^{6}$ cells. Their viability was checked by Trypan Blue (SigmaAldrich, Germany) staining in light microscopy.

Preparation of the neoplastic cell lysates

Laryngeal cancer tissue was obtained during surgical treatment. Tumor samples (without necrotic areas) were digested with $1 \mathrm{mg} / \mathrm{ml}$ of type I collagenase (Biochrome AG, Germany), $1 \mathrm{mg} / \mathrm{ml}$ of type I deoxyribonucleic (Sigma, Germany), and $0.1 \mathrm{mg} / \mathrm{ml}$ of hyaluronidase (Sigma, Germany) and washed twice in RPMI 1640 (Biochrome, Germany). Tumor cells were homogenized by five repeated cycles of quick freezing $\left(-80{ }^{\circ} \mathrm{C}\right)$ and thawing $\left(37^{\circ} \mathrm{C}\right)$. Large particles were removed by centrifugation and after that supernatants were passed through a $20 \mu \mathrm{m}$ pore filter.

\section{Dendritic cells generation}

Peripheral blood mononuclear cells were incubated with anti-CD14 microbeads (Miltenyi-Biotec, Bergisch Gladbach, Germany) and passed through MACS separation columns according to the manufacturer's instructions. The CD14+ cell population was used to prepare Mo-DC. After isolation, the CD14+ cells were washed twice with PBS and seeded into cell culture flasks. The CD14+ cells were cultured in RPMI 1640 medium (BioWhittaker, 
Walkersville, MD, USA) supplemented with $2 \%$ human albumin (Baxter, Austria), $100 \mathrm{IU} / \mathrm{ml}$ penicillin, $50 \mathrm{mg} / \mathrm{ml}$ streptomycin, and $100 \mathrm{mg} / \mathrm{ml}$ neomycin (Sigma-Aldrich, Germany) for $2 \mathrm{~h}$ in $37{ }^{\circ} \mathrm{C}$ and $5 \% \mathrm{CO}_{2}$. After incubation, the non-adherent cells were removed with PBS without $\mathrm{Ca}^{2+}$ and $\mathrm{Mg}^{2+}$ (Biochrom AG, Germany). Adherent cells were grown in the appropriate culture medium for 7 days. On days 1,3 , and 5 of the culture, $1,000 \mathrm{IU} / \mathrm{ml} \mathrm{rhGM}$-CSF (Leukine, Berlex, USA) and $500 \mathrm{IU} / \mathrm{ml}$ rhIL-4 (MiltenyiBiotec, Bergisch Gladbach, Germany) were added. The cells were then divided into two equal parts and the first part was assessed using flow cytometry method without stimulation with tumor cell lysates. Tumor necrosis factor $\alpha$ (rhTNF- $\alpha$, Strathmann, Germany) at a concentration of $50 \mathrm{ng} / \mathrm{ml}$ and the aTCL were added to the second part during the last $48 \mathrm{~h}$ of culture for the maturation and pulsing of the Mo-DC.

The Mo-DC of healthy controls were generated as above but were not pulsed with aTCL due to the absence of cancer tissue in this group. Generated cells were then harvested using Trypsin/EDTA solution (Biochrome, Germany).

\section{Flow cytometric analysis}

We used the followings monoclonal antibodies ( $\mathrm{mAb})$ : anti-CD83 FITC (BD Pharmingen, USA)/anti-B7H1 PE (Biolegend, USA), anti-CD83 FITC (BD Pharmingen, USA)/anti-B7H4 PE (Biolegend, USA), anti-CD83 FITC (BD Bioscience, USA)/anti-CD200 PE (AbD Serotec, USA), and anti-CD83 FITC (BD Bioscience, USA)/antiCD200R PE (AbD Serotec, USA). The cell phenotype characterization was performed using a FACSCalibur cytometer equipped with $488 \mathrm{~nm}$ argon laser (BectonDickinson, USA) and analyzed with CellQuest Software (Becton-Dickinson, USA). We collected 300,000 of events in total. Cell debris and dead cells were excluded from the analysis based on scatter signal.

\section{Statistical analysis}

Statistica 9 PL (Stat Soft Inc.) software was applied to statistical analysis and Mann-Whitney $U$ test was used. Pearson's linear correlation coefficient $(r)$ was calculated to disclose relationships between variables. All results are showed as mean \pm standard deviation (SD), medians, and minimum and maximum values. $p$ value $<0.05$ was considered statistically significant.

\section{Results}

The results are presented in the form of percentage values of the cells with the expression of a given antigen and the mean fluorescence intensity (MFI), which is the mean score of the density of an expression of a given molecule on a cell. Table 1 presents obtained results in G1, G2, G3 LC patients, as in HD.

Our study revealed that the percentage of Mo-DC with an expression of CD83 antigen in patients was statistically lower than in HDs (median $91.28 \%$, range from 55.37 to $99.67 \%$; mean $87.53 \pm 9.94$ vs. $99.77 \%$, range from 99.41 to $99.86 \%$; mean $99.73 \pm 0.14 \%, p \leq 0.0001$ ). There was no difference between the percentages of MoDC generated from patients with G1 and G2 LC $(p=0.823)$. Lower frequencies of CD83+ Mo-DC were noted in patients with G3 LC in comparison to G1 LC $(p=0.017)$. Significantly higher percentages of CD83+ Mo-DC were generated from HD than from G1, G2, and G3 LC patients $(p \leq 0.0001)$, and from G2 than G3 LC patients $(p=0.005)$. Figure 1 illustrates observed results. The differences of CD83 MFI values between the aforementioned groups were also statistically significant $(p \leq 0.0001)$; higher in patients (median 308.44, range from 201.23 to 628.26 ; mean $336.99 \pm 115.39$ ) than in healthy individuals (median 192.01, range from 139.72 to 276.38; mean $199.22 \pm 40.28$ ). Figure 2 presents obtained results.

It has been demonstrated that the percentage of Mo-DC, stimulated with LC antigens, characterized by $\mathrm{B} 7 \mathrm{H} 1$ expression, derived from the group of patients was significantly statistically higher than the frequencies of CD83+ B7H1+ Mo-DC generated from the control group (median $87.81 \%$, range from 42.13 to $99.67 \%$; mean $79.26 \pm 18.74$ vs. $74.66 \%$, range from 42.95 to $94.72 \%$; mean $71.27 \pm 15.71 \%, p=0.041$ ). Obtained results were the most prominent in G3 LC patients (Fig. 3). The MFI of B7H1 was also higher in patients than in HD (median 209.38, range from 78.84 to 623.68; mean $273.21 \pm 151.50$ vs. median 163.82 , range from 102.93 to 261.15; mean $164.83 \pm 46.07, p=0.002$ ). Differences between B7H1 MFI on Mo-DC generated from patients in G1, G2, G3, and from control group are presented in Fig. 4.

The percentage of mature DC with $\mathrm{B} 7 \mathrm{H} 4$ expression was also higher in the tested group than in the control group (median $3.41 \%$, range from 1.14 to $16.16 \%$; mean $4.24 \pm 3.38$ vs. $1.82 \%$, range from 0.47 to $5.97 \%$; mean $1.96 \pm 1.34 \%, p \leq 0.0001)$. Differences between Mo-DC generated from G1, G2, and G3 LC specimens were significant. The highest frequencies of $\mathrm{B} 7 \mathrm{H} 4+$ Mo-DC were found in poorly differentiated LC (Fig. 5). The obtained MFI for B7H4 in the group of the individuals with LC was as follows, median 42.99, range from 11.44 to 90.30 ; mean $44.76 \pm 21.91$, and statistically significantly higher than in HD (median 4.02, range from 1.23 to 7.43 ; mean $4.11 \pm 1.69, p \leq 0.0001$ ), especially in the case of G3 LC (Fig. 6). 
Table 1 Percentages of CD83+, CD83+ CD200+, CD83+ CD200R+, CD83+ B7H1+, and CD83+ B7H4+ Mo-DC generated from laryngeal cancer patients in various histological grades (G1-G3) and from healthy donors, and mean fluorescence intensity (MFI) of analyzed molecules on Mo-DC

\begin{tabular}{|c|c|c|c|c|c|}
\hline & Minimum & Maximum & Mean & Median & Standard deviation \\
\hline \multicolumn{6}{|c|}{ Laryngeal cancer grade $1(\mathrm{G} 1), n=15$ patients } \\
\hline $\mathrm{CD} 83+$ cells $(\%)$ & 71.45 & 99.22 & 90.14 & 95.75 & 9.45 \\
\hline CD83 MFI & 231.16 & 506.69 & 323.43 & 306.30 & 87.70 \\
\hline CD83+ CD200+ cells $(\%)$ & 8.82 & 41.28 & 16.42 & 13.55 & 8.19 \\
\hline CD200 MFI & 41.56 & 153.82 & 66.75 & 50.32 & 40.67 \\
\hline CD83+ CD200R+ cells $(\%)$ & 29.03 & 87.27 & 67.92 & 74.87 & 18.41 \\
\hline CD200R MFI & 188.63 & 451.68 & 274.16 & 242.47 & 88.16 \\
\hline $\mathrm{CD} 83+\mathrm{B} 7 \mathrm{H} 1+$ cells $(\%)$ & 42.13 & 92.01 & 58.31 & 48.48 & 18.86 \\
\hline B7H1 MFI & 78.84 & 281.38 & 154.47 & 164.92 & 70.93 \\
\hline $\mathrm{CD} 83+\mathrm{B} 7 \mathrm{H} 4+$ cells $(\%)$ & 1.14 & 4.02 & 2.11 & 1.83 & 1.01 \\
\hline MFI B7H4 & 11.44 & 52.88 & 24.59 & 19.58 & 14.20 \\
\hline \multicolumn{6}{|c|}{ Laryngeal cancer grade $2(\mathrm{G} 2), n=23$ patients } \\
\hline CD83+ cells $(\%)$ & 55.37 & 99.67 & 89.67 & 94.72 & 10.85 \\
\hline CD83 MFI & 201.23 & 628.26 & 327.35 & 268.68 & 129.43 \\
\hline CD83+ CD200+ cells $(\%)$ & 6.17 & 44.47 & 16.51 & 13.12 & 9.96 \\
\hline CD200 MFI & 49.8 & 166.45 & 95.97 & 108.22 & 38.68 \\
\hline CD83+ CD200R+ cells $(\%)$ & 45.93 & 95.34 & 76.28 & 79.49 & 14.46 \\
\hline CD200R MFI & 239.42 & 504.09 & 318.91 & 289.80 & 78.04 \\
\hline $\mathrm{CD} 83+\mathrm{B} 7 \mathrm{H} 1+$ cells $(\%)$ & 47.94 & 94.83 & 80.89 & 83.68 & 12.12 \\
\hline B7H1 MFI & 153.08 & 335.72 & 214.97 & 201.77 & 43.60 \\
\hline CD83+ B7H4 +cells $(\%)$ & 1.77 & 4.69 & 3.16 & 3.16 & 0.72 \\
\hline MFI B7H4 & 19.58 & 57.92 & 38.86 & 39.58 & 10.37 \\
\hline \multicolumn{6}{|c|}{ Laryngeal cancer grade $3(\mathrm{G} 3), n=22$ patients } \\
\hline CD83+ cells $(\%)$ & 69.27 & 94.49 & 83.52 & 83.79 & 8.26 \\
\hline CD83 MFI & 211.23 & 626.29 & 356.33 & 327.94 & 118.77 \\
\hline CD83+ CD200+ cells $(\%)$ & 6.17 & 42.47 & 15.17 & 13.95 & 8.82 \\
\hline CD200 MFI & 52.97 & 415.09 & 184.09 & 172.44 & 102.56 \\
\hline CD83+ CD200R+ cells $(\%)$ & 33.75 & 94.01 & 70.32 & 82.15 & 18.17 \\
\hline CD200R MFI & 254.34 & 874.18 & 603.04 & 549.01 & 214.64 \\
\hline CD83+ B7H1+ cells $(\%)$ & 61.83 & 100.28 & 91.86 & 95.71 & 10.67 \\
\hline B7H1 MFI & 175.03 & 623.68 & 415.05 & 424.93 & 155.81 \\
\hline CD83+ B7H4+ cells $(\%)$ & 2.26 & 16.16 & 6.82 & 5.38 & 4.41 \\
\hline MFI B7H4 & 23.43 & 90.31 & 63.08 & 63.02 & 20.54 \\
\hline \multicolumn{6}{|l|}{ Healthy donors, $n=15$ persons } \\
\hline CD83+ cells $(\%)$ & 99.41 & 99.86 & 99.73 & 99.77 & 0.14 \\
\hline CD83 MFI & 139.72 & 276.38 & 199.23 & 192.00 & 40.28 \\
\hline CD83+ CD200+ cells $(\%)$ & 6.12 & 22.68 & 11.22 & 10.79 & 3.85 \\
\hline CD200 MFI & 14.41 & 24.47 & 18.16 & 18.25 & 2.83 \\
\hline CD83+ CD200R + cells $(\%)$ & 36.21 & 89.05 & 66.78 & 65.87 & 12.38 \\
\hline CD200R MFI & 16.99 & 124.78 & 81.62 & 86.73 & 24.93 \\
\hline $\mathrm{CD} 83+\mathrm{B} 7 \mathrm{H} 1+$ cells $(\%)$ & 42.95 & 94.72 & 71.27 & 74.66 & 15.70 \\
\hline B7H1 MFI & 102.93 & 261.15 & 164.83 & 163.82 & 46.08 \\
\hline CD83+ B7H4+ cells $(\%)$ & 0.47 & 5.97 & 1.96 & 1.82 & 1.34 \\
\hline MFI B7H4 & 1.23 & 7.43 & 4.11 & 4.02 & 1.69 \\
\hline
\end{tabular}


Fig. 1 Assessment of the frequencies of CD83+ Mo-DC in control group and laryngeal cancer patients with grade 1 , grade 2 , or grade 3 squamous cells carcinoma of the larynx
Fig. 2 Assessment of the CD83 MFI values on Mo-DC in control group and laryngeal cancer patients with grade 1 , grade 2 , or grade 3 squamous cells carcinoma of the larynx

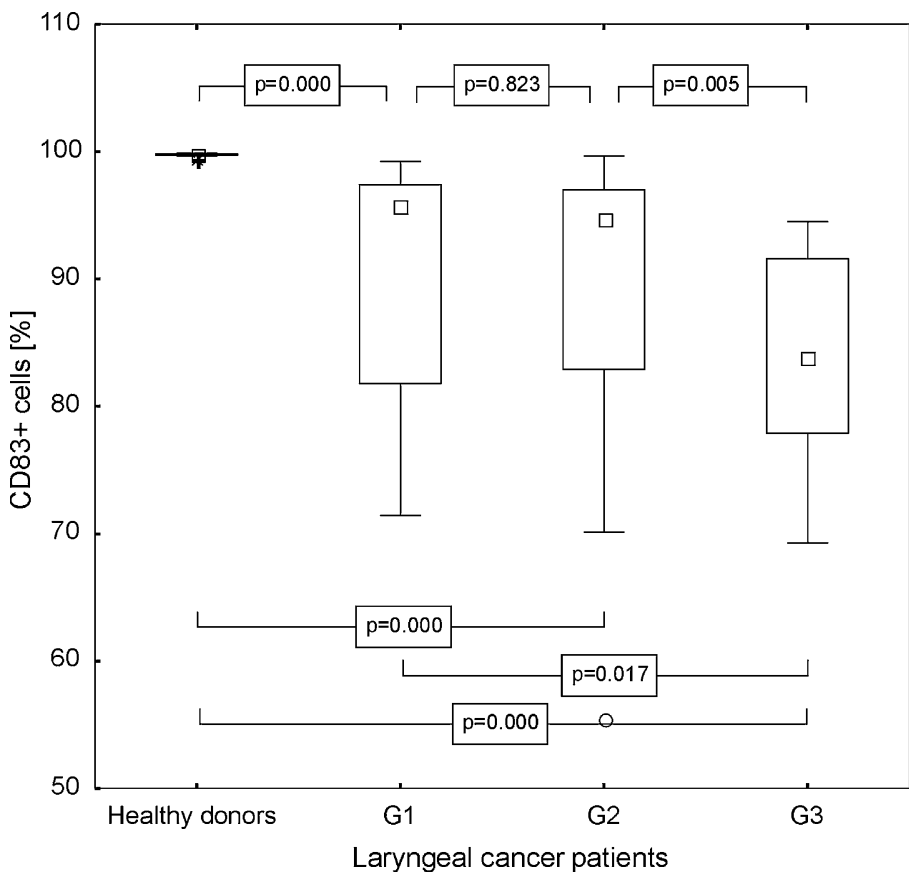

- Median

$25 \%-75 \%$

I Min-Max

O Outliers

* Extreme Outliers

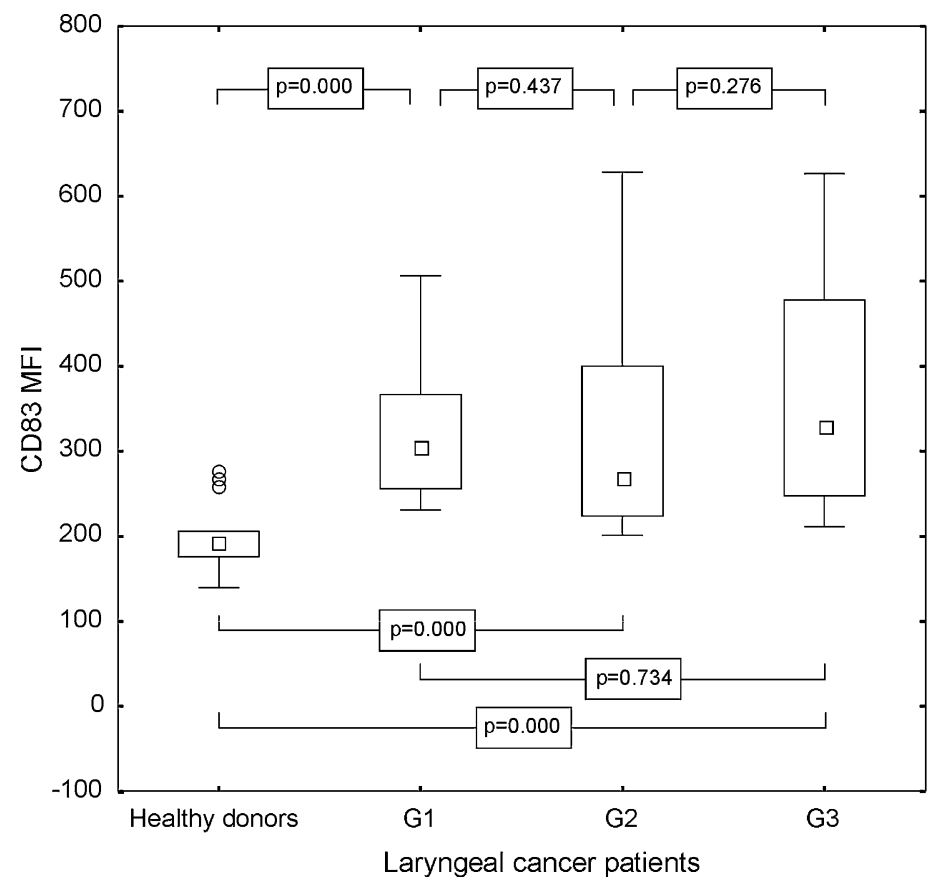

$\square$ Median

$\square$ 25\%-75\%

I Min-Max

o Outliers

- Extreme Outliers
The proportion of $\mathrm{CD} 83+\mathrm{CD} 200+$ cells in patients was higher than in the healthy persons (median $13.71 \%$, range from 6.17 to $44.47 \%$; mean $15.99 \pm 8.99 \%$ vs. median $10.79 \%$, range from 6.12 to $22.68 \%$; mean $11.22 \pm 3.85 \%, p=0.02$ ), and the highest frequencies of the described cells were noted in G3 LC (Fig. 7). Median MFI value of CD200 antigen on the CD83+ Mo-DC from laryngeal cancer patients, stimulated with aTCL, amounted to 109.82 (range from 41.56 to 415.09 ; mean $120.97 \pm 84.68)$ and was statistically significantly higher than on the unpulsed Mo-DC of HDs (median 18.25, range from 14.41 to 24.47 ; mean $18.16 \pm 2.83, p \leq 0.0001)$. In patients suffering from poorly differentiated LC, the highest MFI of CD200 molecule was noted (Fig. 8).

The control group was characterized by a lower percentage value of CD83+ Mo-DC with CD200R antigen expression (median $65.87 \%$, range from 36.21 to $89.05 \%$; mean $65.78 \pm 12.38 \%)$ than individuals with laryngeal cancer (median $79.86 \%$, range from 29.03 to $95.34 \%$; mean $72.01 \pm 16.98 \%$ ), but the statistical significance 
Fig. 3 Assessment of the frequencies of $\mathrm{CD} 83+\mathrm{B} 7 \mathrm{H} 1+$ Mo-DC in control group and laryngeal cancer patients with grade 1 , grade 2 , or grade 3 squamous cells carcinoma of the larynx

Fig. 4 Assessment of the B7H1 MFI values on Mo-DC in control group and laryngeal cancer patients with grade 1 , grade 2, or grade 3 squamous cells carcinoma of the larynx

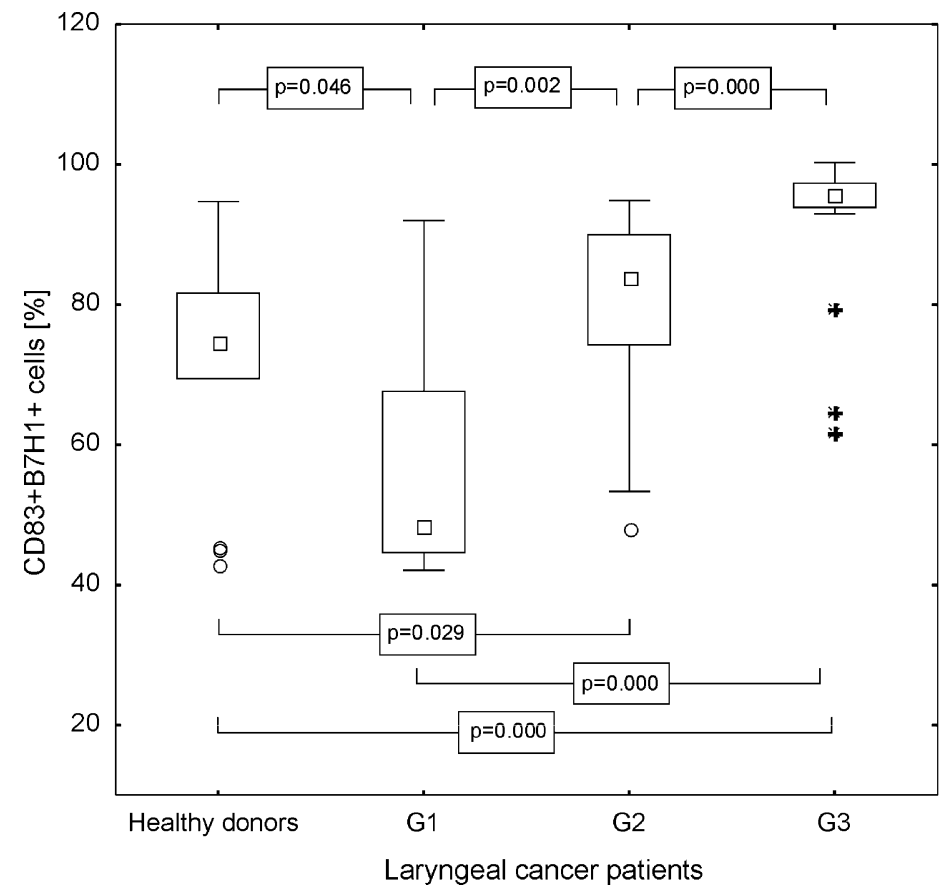

$\square$ Median

$25 \%-75 \%$

I Min-Max

o Outliers

* Extreme Outliers

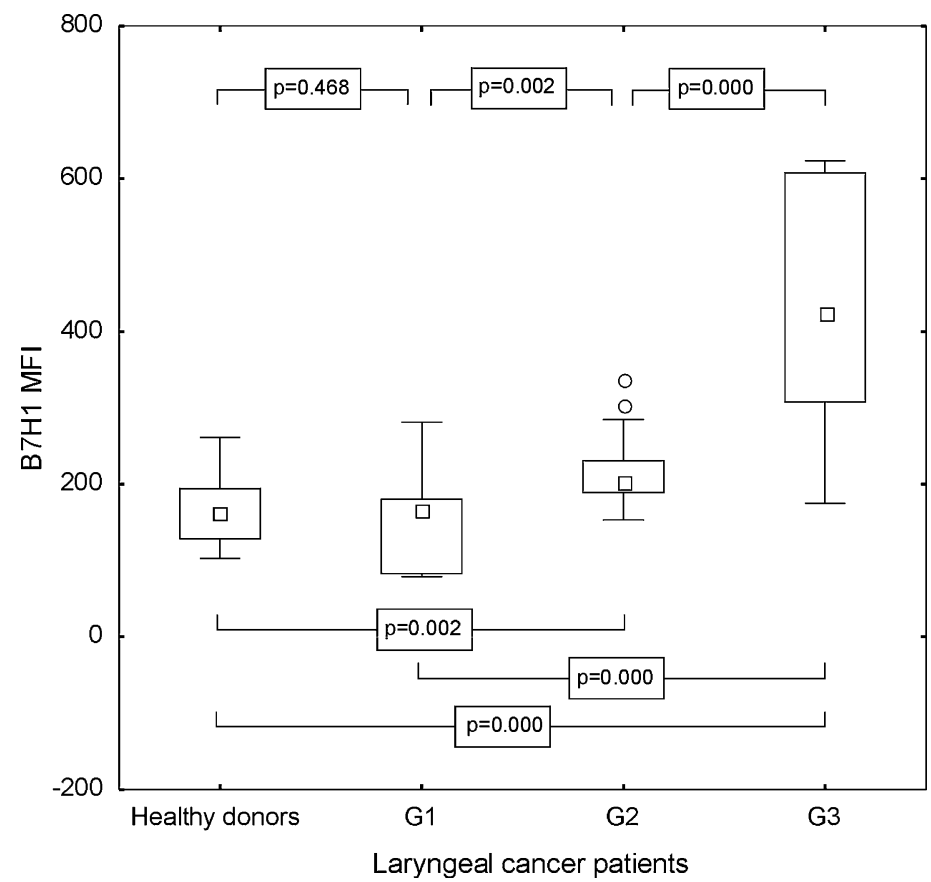

$\square$ Median

25\%-75\%

I Min-Max

o Outliers

* Extreme Outliers was also not revealed ( $p=0.277$, Fig. 9). MFI of CD200 receptor expression on CD83+ Mo-DC among the persons with LC was considerably higher (mean $411.91 \pm 205.74$, median 303.25 , range from 188.63 to 874.18 ) than in the control group (mean $81.62 \pm 24.94$, median 86.73 , range from 16.99 to $124.78, p \leq 0.0001)$ and the highest values ware noted in G3 LC (Fig. 10).

\section{Discussion}

Patients with advanced cancer including squamous cell carcinoma of the head and neck are known to be immunologically compromised [13, 14]. Tumor cells can therefore escape from the immune responses by numerous mechanisms, including the molecule $\mathrm{B} 7 \mathrm{H} 1, \mathrm{~B} 7 \mathrm{H} 4$, and 
Fig. 5 Assessment of the frequencies of CD83+ B7H4+ Mo-DC in control group and laryngeal cancer patients with grade 1 , grade 2 , or grade 3 squamous cells carcinoma of the larynx

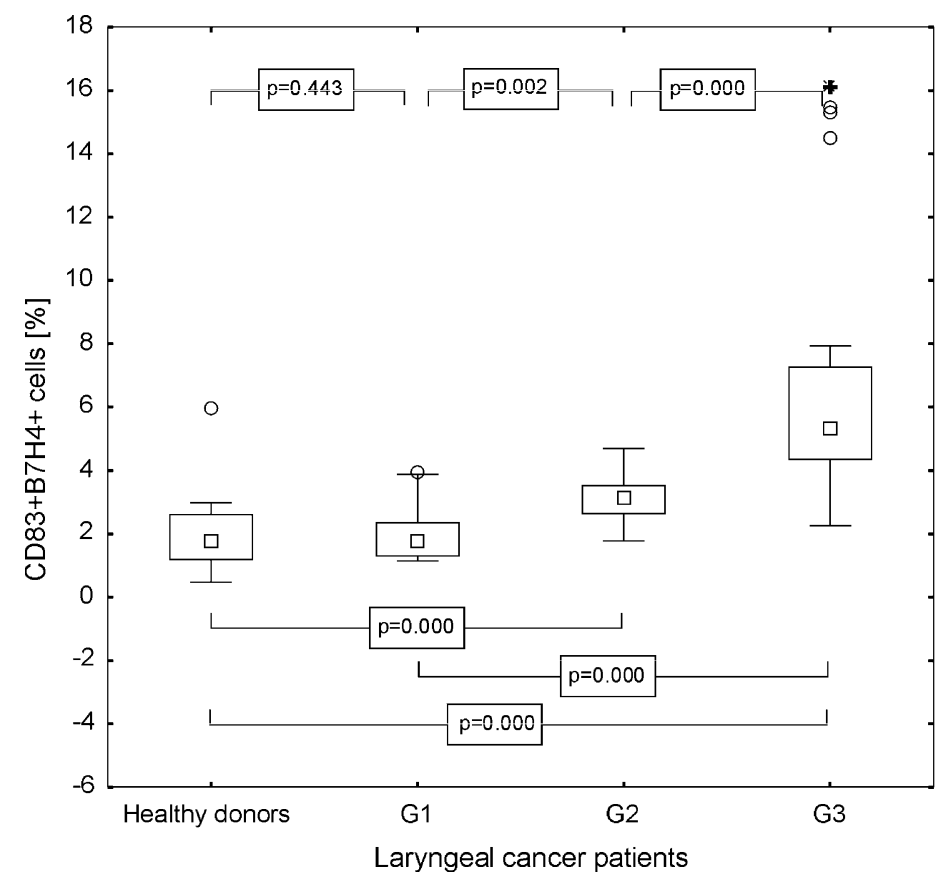

$\square$ Median $\square 25 \%-75 \%$ I Min-Max O Outliers

* Extreme Outliers
Fig. 6 Assessment of the B7H4 MFI values on Mo-DC in control group and laryngeal cancer patients with grade 1 , grade 2, or grade 3 squamous cells carcinoma of the larynx

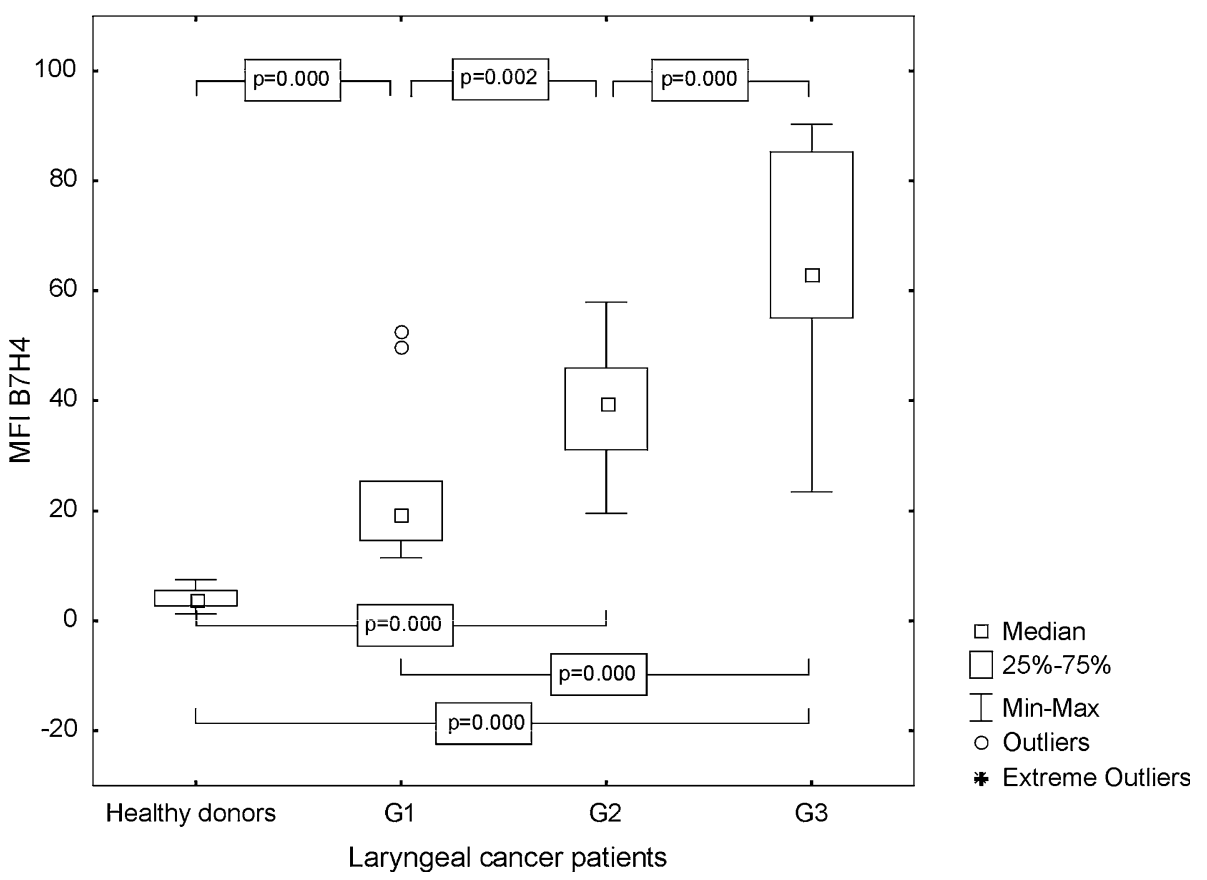

CD200 that acts as a potent suppressor of CD200Rexpressing immune cells [15-17].

B7 molecules on the surface of antigen presenting cells participate in the most important activation cycle in the process of co-stimulation which constitutes a 'second signal' and is essential to activate T lymphocytes properly by means of an interaction with CD28 molecule on T lymphocytes [18]. B7H1 demonstrates a strong expression of activated DC, T lymphocytes, B lymphocytes, and monocytes [19]. Allegedly, B7H1 molecule, which is present on
DC, influences the hindrance of $\mathrm{T}$ lymphocyte proliferation dependent on TCR and the decrease in cytokine production [20]. It can be significant while regulating the immune response and the tolerance induction. In our research, it has been observed statistically significantly higher percentage of $\mathrm{CD} 83+\mathrm{B} 7 \mathrm{H} 1+$ cells in the group of the individuals with LC. The tests conducted on an animal model [21] demonstrated that the obstruction of $\mathrm{B} 7 \mathrm{H} 1$ molecule will result in the increase in interleukin 2 and interferon $\gamma$ production. Our results suggest that Mo-DC of the LC 
Fig. 7 Assessment of the frequencies of CD83+ CD200+ Mo-DC in control group and laryngeal cancer patients with grade 1 , grade 2 , or grade 3 squamous cells carcinoma of the larynx

Fig. 8 Assessment of the CD200 MFI values on Mo-DC in control group and laryngeal cancer patients with grade 1 , grade 2, or grade 3 squamous cells carcinoma of the larynx
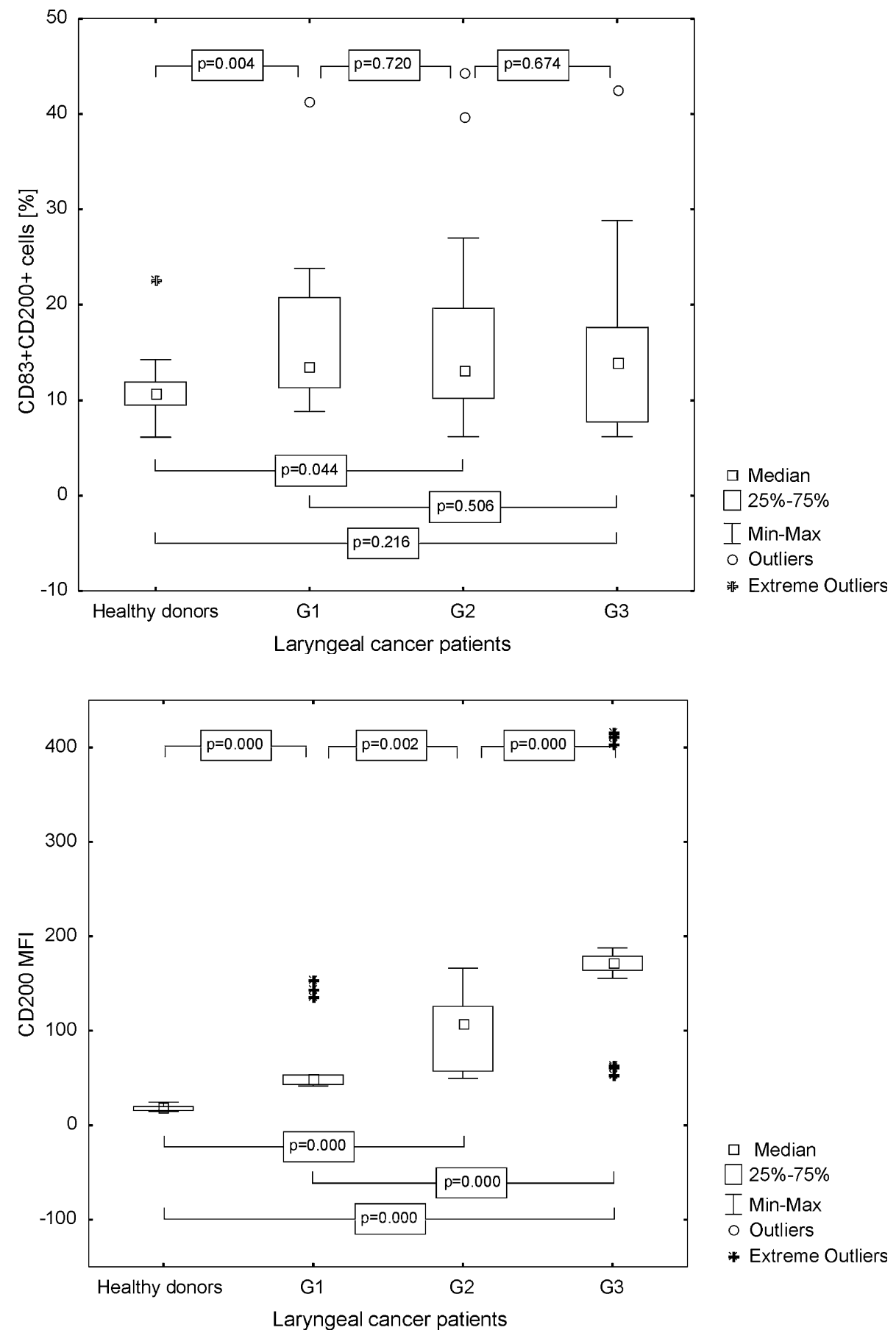

patients demonstrate a hindering influence on the $\mathrm{T}$ lymphocyte activation and proliferation by means of $\mathrm{B} 7 \mathrm{H} 1$ molecule, which is overexpressed especially in LC grade 3.

B7H4 molecule, which interacts with its receptor, also blocks the activation of $\mathrm{T}$ lymphocytes, the production of cytokines and it limits cytotoxicity. The role of $\mathrm{B} 7 \mathrm{H} 4$ is also connected with the prevention of the apoptosis of cancer cells. It has been demonstrated that interleukin 10 increases the expression of B7H4 on the surface of human cells which presents an antigen and the factor which stimulates the colonies of granulocytes and macrophages and interleukin 4 decreases the expression of this molecule [22]. Our study indicates that there is an overexpression of B7H4 molecule on DC generated from patients with LC and it corresponds with histological grade of LC.

Expression of CD200 has been implicated in multiple types of human cancer including squamous cell carcinoma. However, the impact of tumor expression of CD200 on tumor immunity remains poorly understood and the expression of the discussed molecules was not assessed on 
Fig. 9 Assessment of the frequencies of CD83+ CD200R+ Mo-DC in control group and laryngeal cancer patients with grade 1 , grade 2 , or grade 3 squamous cells carcinoma of the larynx

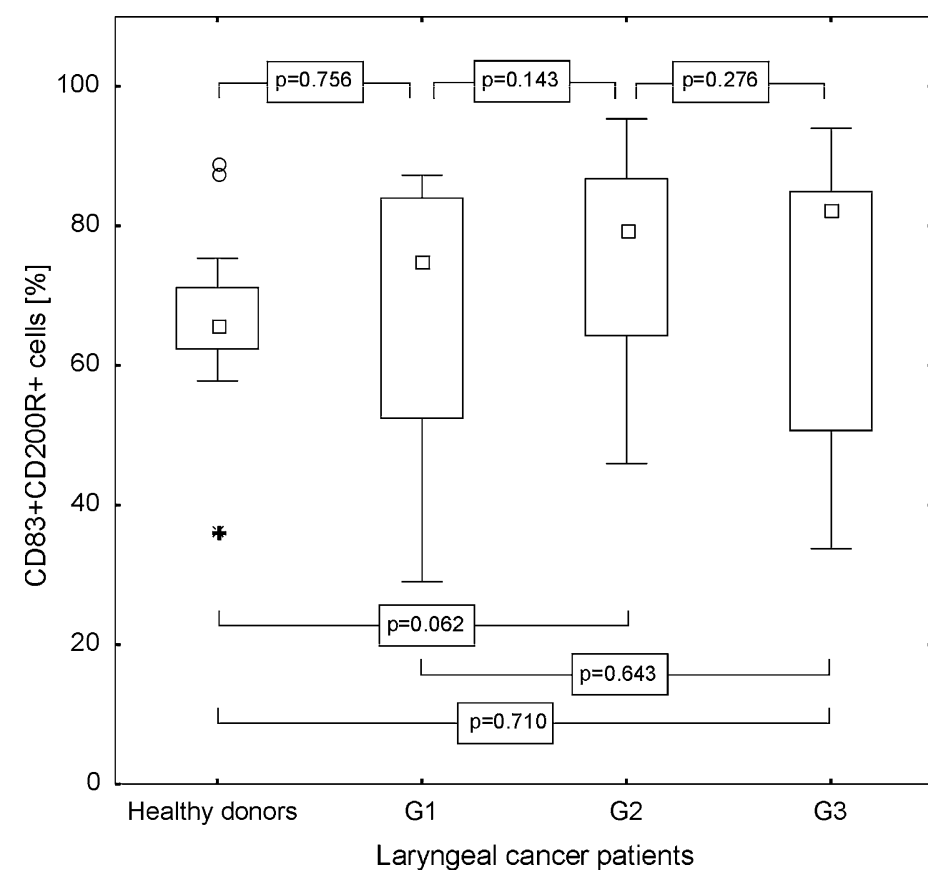

$\square$ Median

$\square$ 25\%-75\%

I Min-Max

o Outliers

* Extreme Outliers
Fig. 10 Assessment of the CD200R MFI values on Mo-DC in control group and laryngeal cancer patients with grade 1 , grade 2, or grade 3 squamous cells carcinoma of the larynx

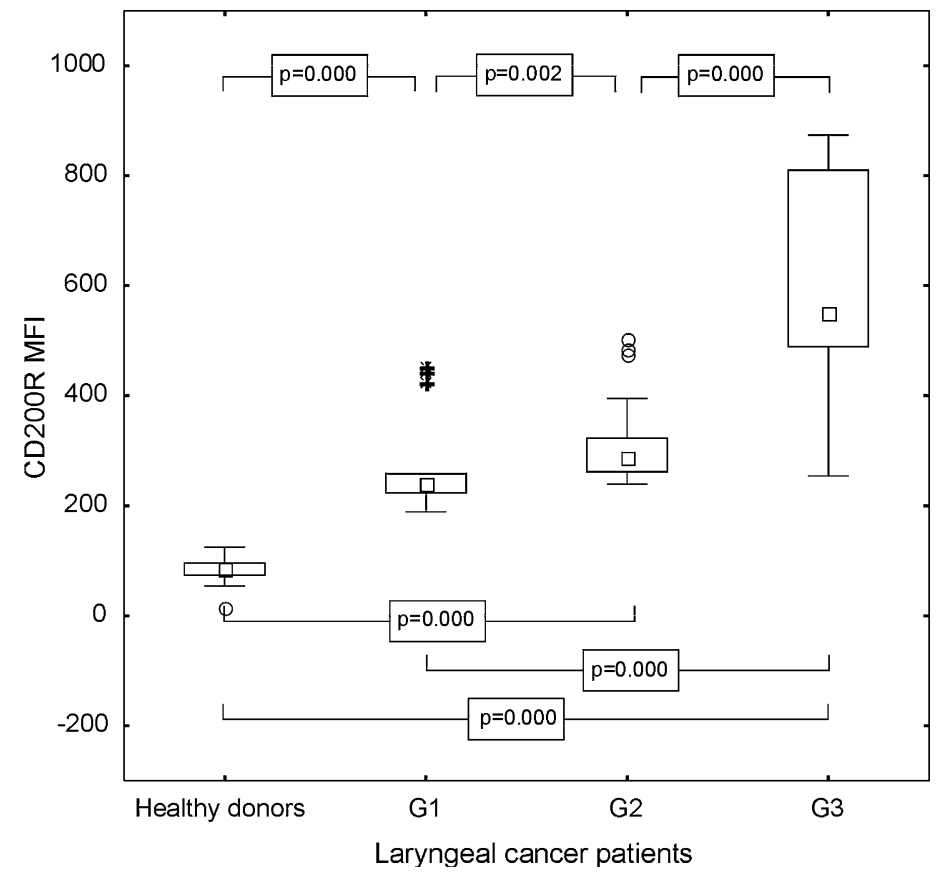

$\square$ Median

$25 \%-75 \%$

I Min-Max

o Outliers

* Extreme Outliers the Mo-DC of LC patients. CD200 molecule or its natural ligand plays role in the delivery of a tolerizing signal. Our study revealed that there is a significant relationship between the presence and grade of LC, and the expression of CD200 and CD200R molecules on the Mo-DC pulsed with autologous cancer cell lysates. CD83+ Mo-DC of healthy controls present significantly lower MFI values of CD200 and CD200R antigen expression than the same type of cells after the stimulation. This finding means that pulsing DC with laryngeal cancer tumor lysates would increase the expression of CD200s known inhibitory effect on myeloid cells and is quite surprising. Many studies published before $[23,24]$ used the concept of pulsing DC with autologous tumor lysates to elicit an effective antitumor immune response. CD200 positive cells can inhibit the stimulation of type-1 cytokine production by bonemarrow-derived B7-1 (and B7-2) positive DC [25]. Other data have implied an immunoregulatory role for CD200 expression, assayed by altered cytokine production in vitro from cells stimulated in the presence or absence of 
expressed CD200 [26], which is nowadays widely accepted as immunosuppressive factor. Hoek et al. [27] suggested that binding of CD200 antigen with its specific receptor CD200R on myeloid cells such as macrophages, is responsible for down regulation of its activity, so the tissue damage caused by macrophages might be naturally reduced. Rosenblum et al. [28] marked that higher expressions of CD200 were on DC that undergo apoptosis. The most recent study, provided by Seeds et al. [29] shows that CD200 knock-out macrophages produce more IFN $\alpha$ than wild-type macrophages in response to stimulus, what was consistent with CD200s known inhibitory effect on myeloid cells. In contrast, blocking CD200 with an antiCD200 mAb resulted in reduced IFN $\alpha$ production. This suggests there could be a differential effect of CD200 on IFN induction pathways in DC and macrophages. Moreover, authors' results support the hypothesis that CD200 is involved in virally induced type I IFN induction.

A number of mAbs have been successfully used in solid cancers. Because CD200 does not have a signaling domain it appears that anti-CD200 Abs do not directly affect targeted tumor cells, and Kretz-Rommel et al. [30] demonstrated that the anti-CD200 mAbs, as expected, did not inhibit tumor cell proliferation or directly induce cell death [31]. Therefore, antagonistic anti-CD200 Abs are expected to exert their effect by blocking immune suppression. Our data indicate that also DC-based immunotherapy supported by the use of mAb anti-CD200 may be effective in the treatment of laryngeal cancer in future, but further studies analyzing the influence of both mAb anti-CD200 and antiCD200R, and Mo-DC on autologous laryngeal cancer cell cultures are essential.

\section{Conclusions}

Our results prove that there is a relation between the presence of laryngeal cancer and the expression of $\mathrm{B} 7 \mathrm{H} 1$, B7H4, CD200, and CD200R regulatory molecules on the CD83+ Mo-DC pulsed with autologous cancer cell lysates. Strong association of LC grade and the tested antigens expression suggests a critical role for these proteins in LC biology. The expression of the aforementioned tolerogenic molecules on mature dendritic cells can be responsible for the failure of the immunotherapy of squamous cell carcinoma of the larynx with the use of DC, which have been stimulated with autologous cancer cells lysates. The implementation of the B7H1, B7H4, and CD200 inhibitors to DC cancer vaccines seems to be appropriate, and could make the immune system of a host more sensitive to cancer antigens by means of unblocking the hindering influence of the mentioned molecules on the cytotoxicity of $\mathrm{T}$ lymphocytes.
Acknowledgments This study was supported by research grant No. N N403 088535 from State Funds for Scientific Research.

Conflict of interest Authors declare no conflict of interest.

Open Access This article is distributed under the terms of the Creative Commons Attribution License which permits any use, distribution, and reproduction in any medium, provided the original author(s) and the source are credited.

\section{References}

1. Yu Q, Zhang X, Ji C, Yang H, Gao M, Hong S, Hu G (2012) Survival analysis of laryngeal carcinoma without laryngectomy, radiotherapy, or chemotherapy. Eur Arch Otorhinolaryngol 269:2103-2109

2. Chen YF, Luo RZ, Li Y, Cui BK, Song M, Yang AK, Chen WK (2013) High expression levels of COX-2 and P300 are associated with unfavorable survival in laryngeal squamous cell carcinoma. Eur Arch Otorhinolaryngol 270:1009-1017

3. Seiferlein E, Haderlein T, Schuster M, Gräßel E, Bohr C (2012) Correlation between coping strategies and subjective assessment of the voice-related quality of life of patients after resection of T1 and T2 laryngeal tumours. Eur Arch Otorhinolaryngol 269:2091-2096

4. Sakakura K, Chikamatsu K, Takahashi K, Whiteside T, Furuya N (2006) Maturation of circulating dendritic cells and imbalance of T-cell subsets in patients with squamous cell carcinoma of the head and neck. Cancer Immunol Immunother 55:151-159

5. Pletinckx K, Döhler A, Pavlovic V, Lutz MB (2011) Role of dendritic cell maturity/costimulation for generation, homeostasis, and suppressive activity of regulatory T-cells. Front Immunol 2:39. doi:10.3389/fimmu.2011.00039

6. Ichikawa M, Chen L (2005) Role of B7-H1 and B7-H4 molecules in down-regulating effector phase of T-cell immunity: novel cancer escaping mechanisms. Front Biosci 10:2856-2860

7. Zheng X, Li XD, Wu CP, Lu BF, Jiang JT (2012) Expression of costimulatory molecule $\mathrm{B} 7-\mathrm{H} 4$ in human malignant tumors. Onkologie 3511:700-705

8. Barclay AN, Clark MJ, McCaughan GW (1986) Neuronal/lymphoid membrane glycoprotein MRC OX-2 is a member of the immunoglobulin superfamily with a light-chain-like structure. Biochem Soc Symp 51:149-157

9. McWhirter JR, Kretz-Rommel A, Saven A, Maruyama T, Potter KN, Mockridge CI, Ravey EP, Qin F, Bowdish KS (2006) Antibodies selected from combinatorial libraries block a tumor antigen that plays a key role in immunomodulation. Proc Natl Acad Sci USA 103:1041-1046

10. Wright GJ, Jones M, Puklavec MJ, Brown MH, Barclay AN (2001) The unusual distribution of the neuronal/lymphoid cell surface CD200 (OX2) glycoprotein is conserved in humans. Immunology 102:173-179

11. Wong KK, Khatri I, Shaha S, Spaner DE, Gorczynski RM (2010) The role of CD200 in immunity to B cell lymphoma. J Leukoc Biol 88:361-372

12. Stumpfova M, Ratner D, Desciak EB, Eliezri YD, Owens DM (2010) The immunosuppressive surface ligand CD200 augments the metastatic capacity of squamous cell carcinoma. Cancer Res 70:2962-2972

13. Hadden JW (1997) The immunopharmacology of head and neck cancer: an update. Int J Immunopharmacol 11(12):629-644

14. Richtsmeier WJ (1997) Immunology of head and neck cancer. Bull Am Coll Surg 82:32-53 
15. Hoek RM, Ruuls SR, Murphy CA (2000) Down: regulation of the macrophage lineage through interaction with OX2 (CD200). Science 290:1768-1771

16. Wright GJ, Puklavec MJ, Willis AC (2000) Lymphoid/neuronal cell surface OX2 glycoprotein recognizes a novel receptor on macrophages implicated in the control of their function. Immunity $13: 233-242$

17. Gorczynski R, Chen Z, Kai Y, Lee L, Wong S, Marsden PA (2004) CD200 is a ligand for all members of the CD200R family of immunoregulatory molecules. J Immunol 172:7744-7749

18. Njau MN, Jacob J (2013) The CD28/B7 pathway: a novel regulator of plasma cell function. Adv Exp Med Biol 785:67-75

19. Yamazaki T, Akiba H, Koyanagi A, Azuma M, Yagita H, Okumura K (2005) Blockade of B7-H1 on macrophages suppresses CD4+ T-cell proliferation by augmenting IFN-gammainduced nitric oxide production. J Immunol 175:1586-1592

20. Mirza N, Duque MA, Dominguez AL, Schrum AG, Dong H, Lustgarten J (2010) B7-H1 expression on old CD8+ T cells negatively regulates the activation of immune responses in aged animals. J Immunol 184:5466-5474

21. Kim HK, Guan H, Zu G, Li H, Wu L, Feng X et al (2006) Highlevel expression of $\mathrm{B} 7-\mathrm{H} 1$ molecules by dendritic cells suppresses the function of activated T cells and desensitizes allergenprimed animals. J Leukoc Biol 79:686-695

22. Qian Y, Shen L, Xu C, Wu Z, Brockmeyer NH, Altmeyer P, Wu N, Yao HP (2011) Development of a novel monoclonal antibody to B7-H4: characterization and biological activity. Eur J Med Res $16: 295-302$

23. Fields RC, Shimizu K, Mulé JJ (1998) Murine dendritic cells pulsed with whole tumor lysates mediate potent antitumor immune responses in vitro and in vivo. Proc Natl Acad Sci USA 95:9482-9487
24. Asavaroengchai W, Kotera Y, Mulé JJ (2002) Tumor lysatepulsed dendritic cells can elicit an effective antitumor immune response during early lymphoid recovery. Proc Natl Acad Sci USA 99:931-936

25. Gorczynski L, Chen Z, Hu J, Kai G, Ramakrishna V, Gorczynski RM (1999) Evidence that an OX-2 positive cell can inhibit the stimulation of type 1 cytokine production by bone marrowderived B7-1 (and B7-2)-positive dendritic cells. J Immunol 162:774-781

26. Borriello F, Lederer J, Scott S, Sharpe AH (1997) MRC OX-2 defines a novel $\mathrm{T}$ cell costimulatory pathway. J Immunol 158:45-49

27. Hoek RM, Ruuls SR, Murphy CA (2000) Down: regulation of the macrophage lineage through interaction with OX2 (CD200). Science 290:1768-1771

28. Rosenblum MD, Olasz E, Woodliff JE (2004) CD200 is a novel p53-target gene involved in apoptosis-associated immune tolerance. Blood 103:2691-2698

29. Seeds RE, Mukhopadhyay S, Jones IM, Gordon S, Miller JL (2011) The role of myeloid receptors on murine plasmacytoid dendritic cells in induction of type I interferon. Int Immunopharmacol 11:794-801

30. Kretz-Rommel A, Qin F, Dakappagari N, Cofiell R, Faas SJ, Bowdish KS (2008) Blockade of CD200 in the presence or absence of antibody effector function: implications for antiCD200 therapy. J Immunol 180:699-705

31. Kretz-Rommel A, Qin F, Dakappagari N, Ravey EP, McWhirter J, Oltean D, Frederickson S, Maruyama T, Wild MA, Nolan MJ (2007) CD200 expression on tumor cells suppresses antitumor immunity: new approaches to cancer immunotherapy. J Immunol 178:5595-5605 